Supporting Information

\title{
Pre-lithiation of $\mathrm{Li}\left(\mathrm{Ni}_{1-\mathrm{x}-\mathrm{y}} \mathrm{Mn}_{\mathrm{x}} \mathrm{Co}_{\mathrm{y}}\right) \mathrm{O}_{2}$ Materials Enabling to Enhance Performance for Li-Ion Battery
}

Zhongzhen Wu, ${ }^{a, 1}$ Shunping Ji, ${ }^{a, 1}$ Zongxiang Hu, ${ }^{a, 1}$ Jiaxin Zheng, ${ }^{a}$ Shu Xiao, ${ }^{a}$ Yuan Lin, ${ }^{a}$ Kang Xu, Khalil Amine ${ }^{c}$ and Feng Pan ${ }^{a, *}$

${ }^{\text {a }}$ School of Advanced Materials, Peking University Shenzhen Graduate School, Shenzhen 518055, China.

${ }^{\mathrm{b}}$ U. S. Army Research Laboratory, Adelphi, MD20783, United States.

${ }^{\mathrm{c}}$ Electrochemical Technology Program, Chemical Sciences and Engineering Division, Argonne National Laboratory, Argonne, IL 60439, United States.

${ }^{*}$ Corresponding author. Tel/Fax: +86-755-26033200.

E-mail address: panfeng@pkusz.edu.cn (F. Pan) 
Figure S1. The morphology of the prepared $\mathrm{Li}\left(\mathrm{Ni}_{1-\mathrm{x}-\mathrm{y}} \mathrm{Mn}_{\mathrm{x}} \mathrm{Co}_{\mathrm{y}}\right) \mathrm{O}_{2}$ particles.

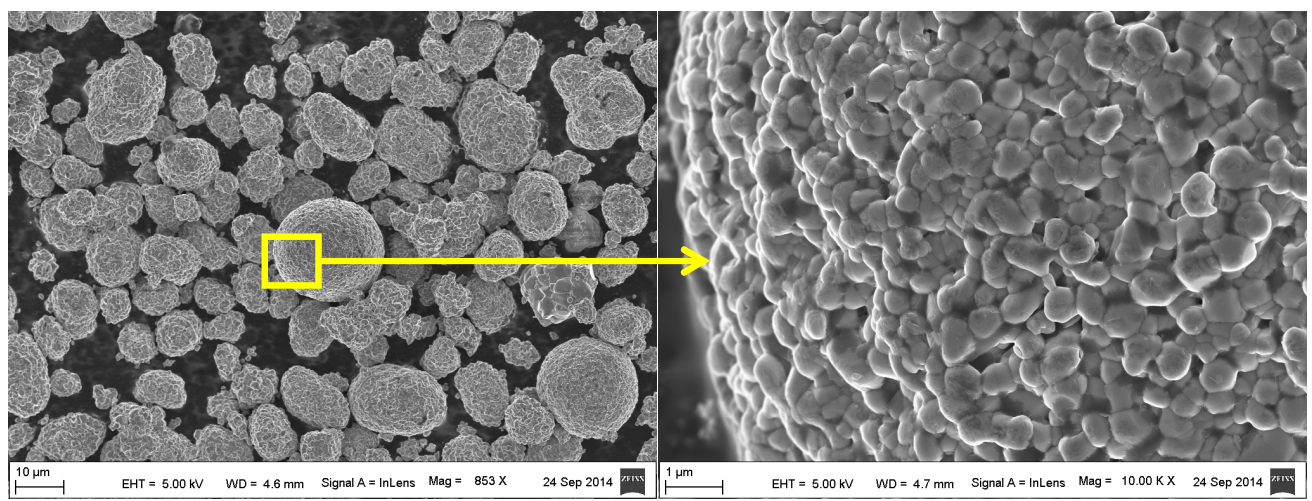

Figure S2. Characterizations at different charge/discharge states on the voltage profile of the $\mathrm{Li}\left(\mathrm{Ni}_{0.7} \mathrm{Mn}_{0.15} \mathrm{Co}_{0.15}\right) \mathrm{O}_{2}$ materials in the pre-lithiation cycle: a) different charge/discharge states, b) composition at charge/discharge states by ICP-AES, c) XRD patterns at charge/discharge states, and d) the magnification of XRD data.

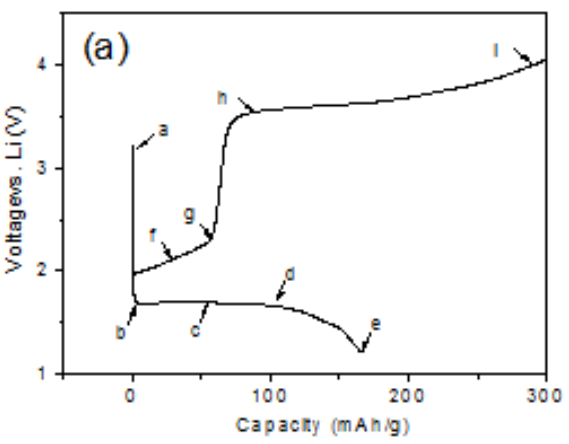

$\begin{array}{ccccc}\text { (b) } & \mathrm{Li} & \mathrm{Ni} & \mathrm{Mn} & \mathrm{Co} \\ \mathrm{g} & 0.95 & 0.69 & 0.16 & 0.15 \\ \mathrm{~b} & 1.05 & 0.64 & 0.17 & 0.15 \\ \mathrm{c} & 1.36 & 0.64 & 0.17 & 0.15 \\ \mathrm{~d} & 1.44 & 0.63 & 0.17 & 0.15 \\ \mathrm{e} & 1.59 & 0.64 & 0.17 & 0.15 \\ \mathrm{f} & 1.43 & 0.64 & 0.16 & 0.15 \\ \text { g } & 1.28 & 0.64 & 0.17 & 0.15 \\ \mathrm{~h} & 1.17 & 0.64 & 0.17 & 0.15 \\ \text { i } & 0.92 & 0.63 & 0.17 & 0.15\end{array}$

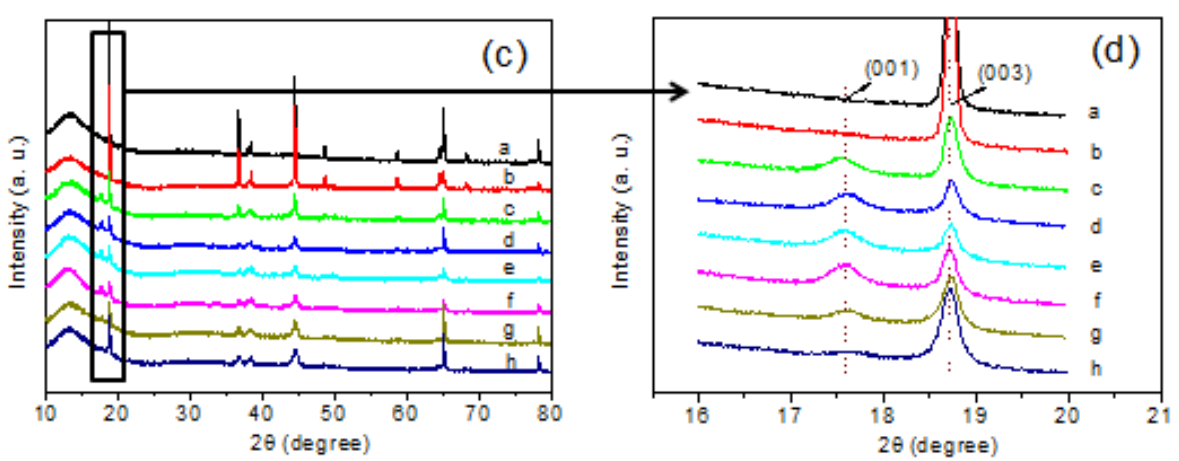


Figure S3. Characterizations at different charge/discharge states on the voltage profile of the $\mathrm{Li}\left(\mathrm{Ni}_{0.6} \mathrm{Mn}_{0.2} \mathrm{Co}_{0.2}\right) \mathrm{O}_{2}$ materials in the pre-lithiation cycle: a) different charge/discharge states, b) composition at charge/discharge states by ICP-AES, c) XRD patterns at charge/discharge states, and d) the magnification of XRD data.

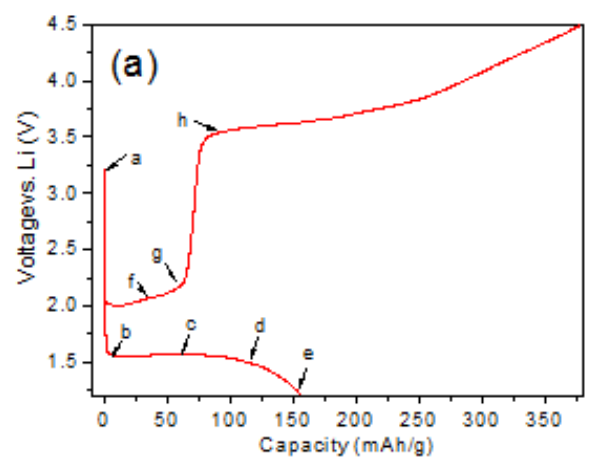

$\begin{array}{ccccc}\text { (b) } & \mathrm{Li} & \mathrm{Ni} & \mathrm{Mn} & \mathrm{Co} \\ \mathrm{a} & 1.06 & 0.59 & 0.21 & 0.2 \\ \mathrm{~b} & 1.19 & 0.62 & 0.21 & 0.2 \\ \mathrm{c} & 1.41 & 0.6 & 0.21 & 0.2 \\ \mathrm{~d} & 1.53 & 0.6 & 0.21 & 0.2 \\ \mathrm{e} & 1.69 & 0.6 & 0.21 & 0.2 \\ \mathrm{f} & 1.5 & 0.62 & 0.2 & 0.2 \\ \mathrm{~g} & 1.39 & 0.63 & 0.21 & 0.2 \\ \mathrm{~h} & 1.26 & 0.62 & 0.21 & 0.2\end{array}$
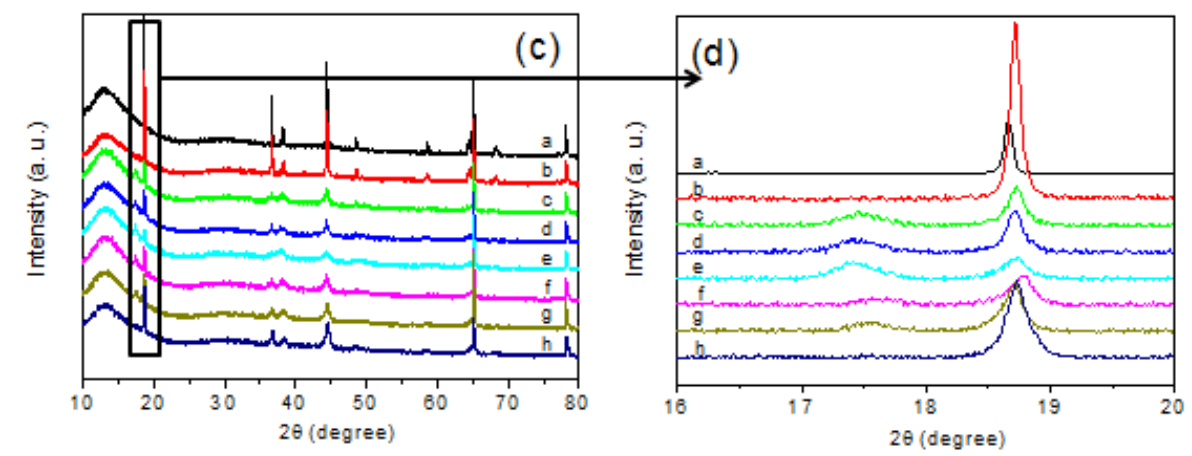

Figure S4. XRD characterizations at different charge/discharge states on the voltage profile of the $\mathrm{Li}\left(\mathrm{Ni}_{0.42} \mathrm{Mn}_{0.42} \mathrm{Co}_{0.16}\right) \mathrm{O}_{2}$ materials in the pre-lithiation cycle.

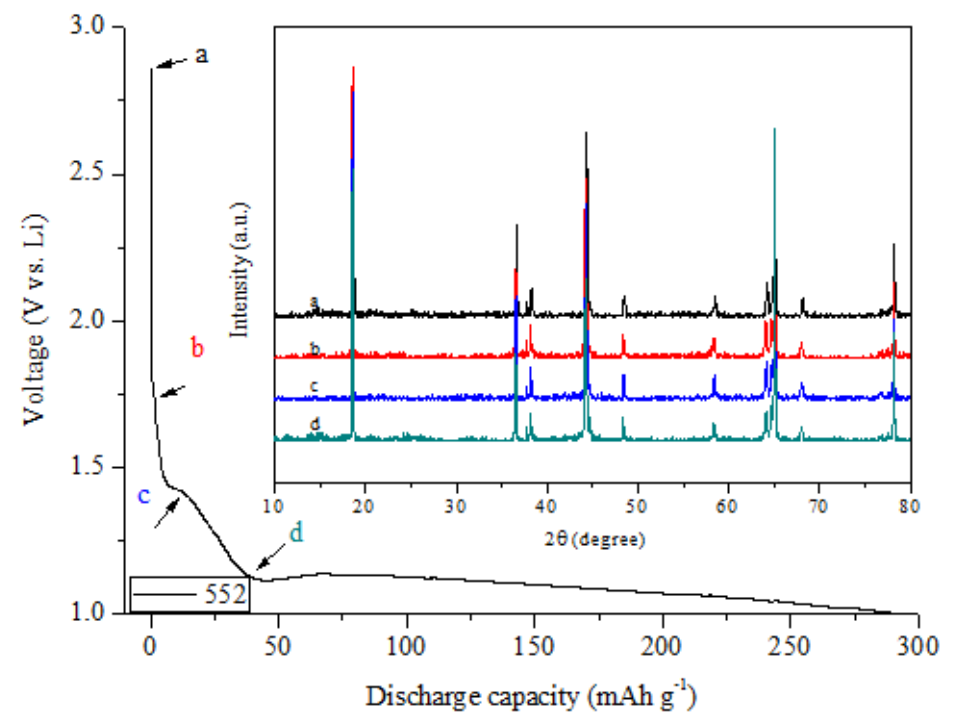


Figure S5. XRD characterizations at different charge/discharge states on the voltage profile of the $\mathrm{Li}\left(\mathrm{Ni}_{0.4} \mathrm{Mn}_{0.4} \mathrm{Co}_{0.2}\right) \mathrm{O}_{2}$ materials in the pre-lithiation cycle.

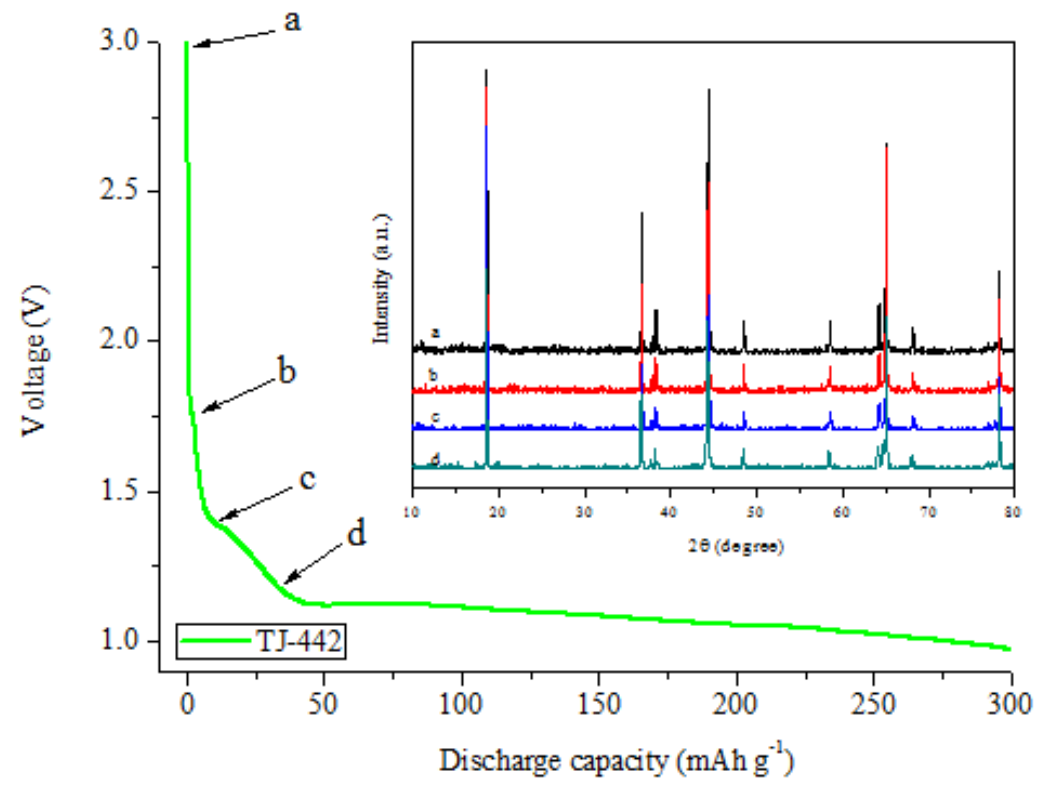

Figure S6. XRD characterizations at different charge/discharge states on the voltage profile of the $\mathrm{Li}\left(\mathrm{Ni}_{0.3} \mathrm{Mn}_{0.3} \mathrm{Co}_{0.3}\right) \mathrm{O}_{2}$ materials in the pre-lithiation cycle.

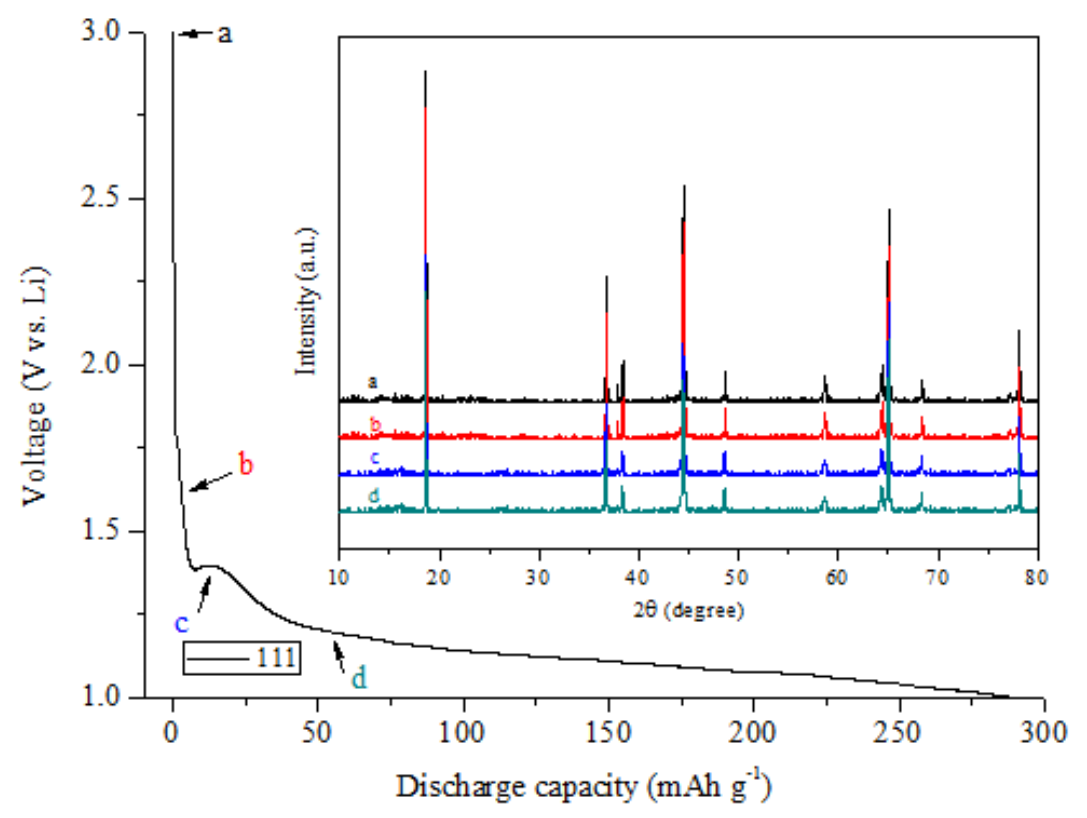


Figure S7. Calculated structures for pre-lithiation group $\mathrm{Li}_{2} \mathrm{MO}_{2}$ (for $\mathbf{N M C 5 3 2 ,}$

\section{NMC622, NMC71515, NMC811).}

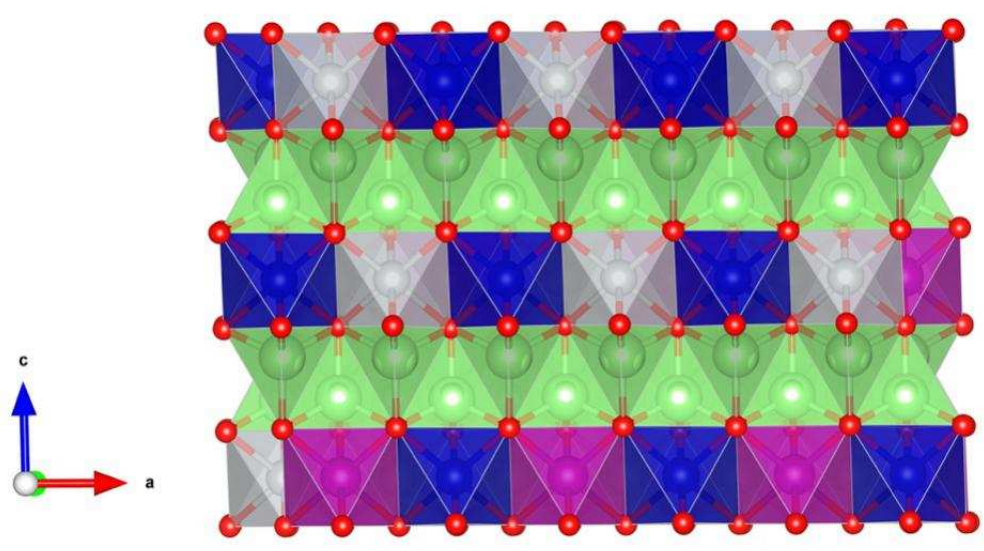

Figure S8. XPS characterizations $\mathrm{Li}\left(\mathrm{Ni}_{0.42} \mathrm{Mn}_{0.42} \mathrm{Co}_{0.16}\right) \mathrm{O}_{2}$ at different charging/discharging states showed in the insert of Figure 9a).
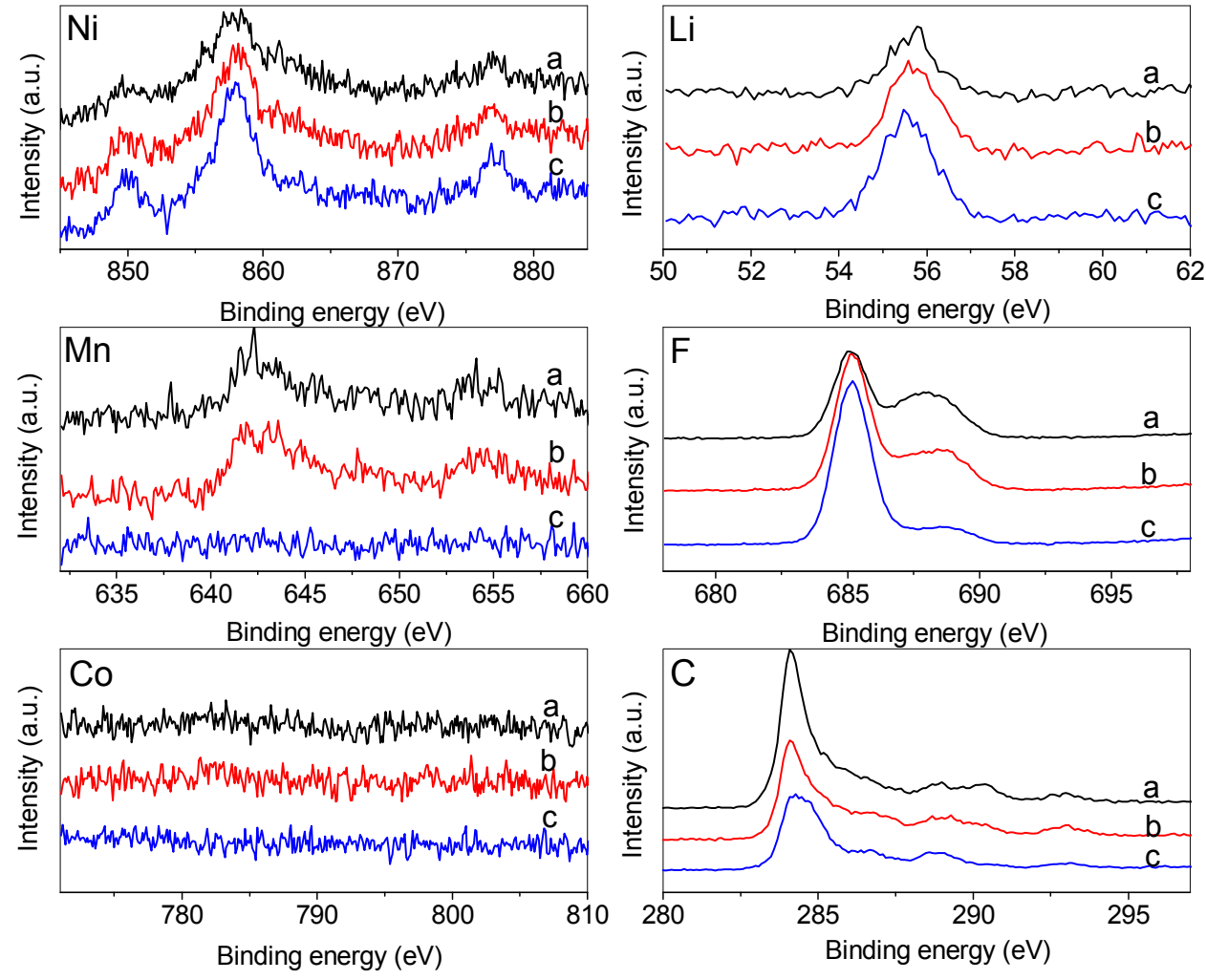
Figure S9. XPS characterizations $\mathrm{Li}\left(\mathrm{Ni}_{0.5} \mathrm{Mn}_{0.3} \mathrm{Co}_{0.2}\right) \mathrm{O}_{2}$ at different charging/discharging states showed in the insert of Figure $9 \mathrm{~b}$ ).
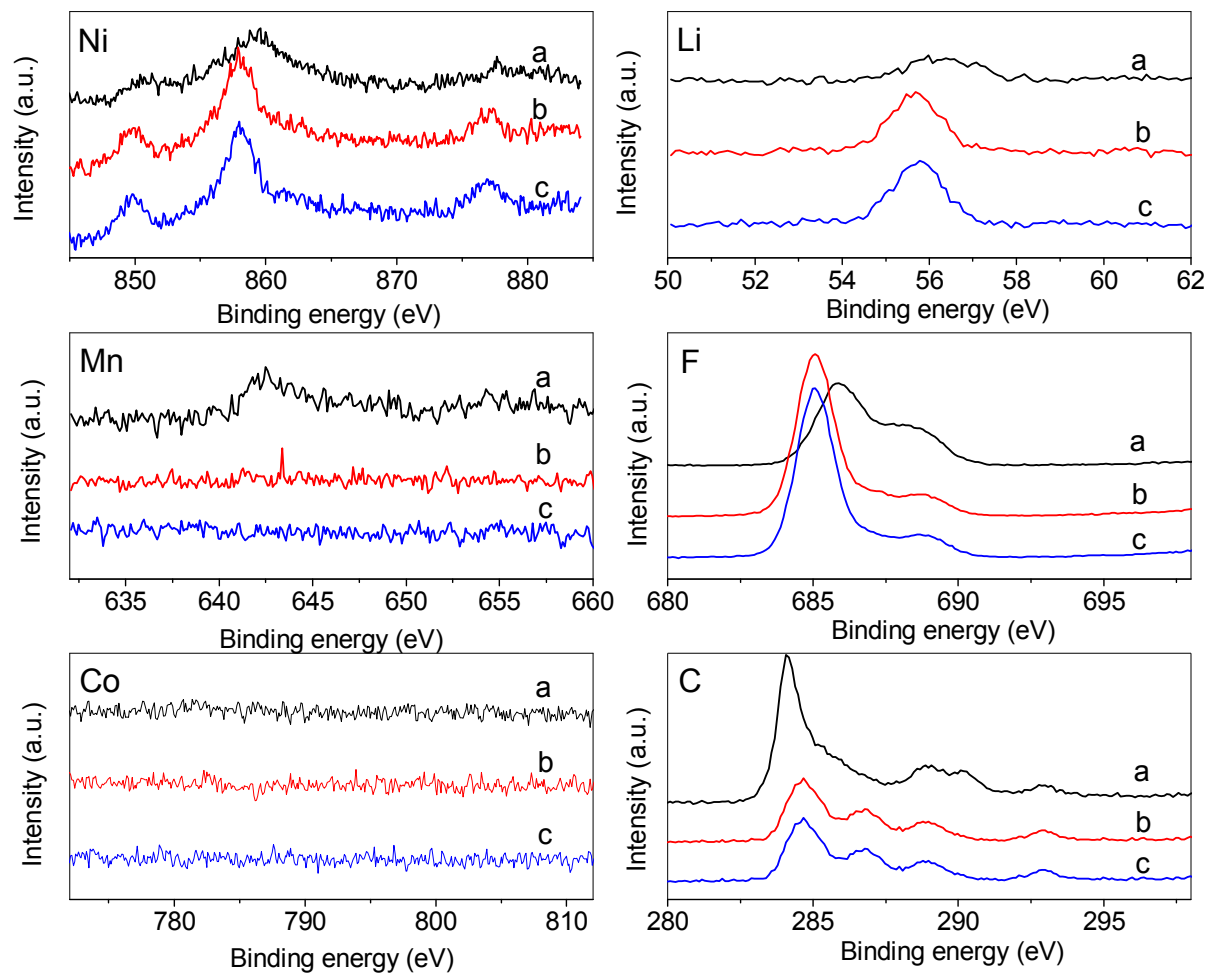